\title{
RANCANG BANGUN SISTEM PENELITIAN DAN PENGABDIAN MASYARAKAT UNIVERSITAS BANGKA BELITUNG BERBASIS WEB SERVER
}

\author{
Ghiri Basuki Putra \\ Jurusan Teknik Elektro Fakultas Teknik Universitas Bangka Belitung \\ E-mail: ghiri-basuki@ubb.ac.id
}

\begin{abstract}
Tridharma Perguruan Tinggi is Teaching, Research and Community Service that must be implemented by every lecturer. Sources of funding for research and Community Service for university lecturers vary, ranging from university level as well as from the Ministry of Research and Higher Education. At the University of Bangka Belitung (UBB), the process of submitting research proposals and Community Service to lecturers is still done manually and there is no online system to support and simplify the proposal submission process and proposal assessment. As for the national level has been using a system called Information Systems Research and Community Service or abbreviated simlitabmas that can be used by all lecturers in Indonesia in submitting research proposals and Community Service to get funding. In the design of research system and dedication, build a system like simlitabmas from Risetdikti to facilitate lecturers in submitting research proposal of university level online and can be done online proposal assessment by university level accessor also online. In this research, build design Lecturer Research and Service System Based Webserver online. The system is built with a web-based integrated system using PHP and MySQL databases. So without printing the proposal and save the cost of printing and paper, lecturers can make submission of research proposal and community service.
\end{abstract}

Keywords: Community Service, Database, Research, Web Server

\section{INTISARI}

Tridharma Perguruan Tinggi adalah Pengajaran, Penelitian dan Pengabdian Masyarakat yang wajib dilaksanakan oleh setiap dosen. Sumber dana untuk Penelitian dan Pengabdian Masyarakat bagi dosen perguruan tinggi ada bermacam macam, mulai dari tingkat Perguruan Tinggi maupun dari Kementerian Riset dan Pendidikan Tinggi. Di Universitas Bangka Belitung (UBB), proses pengajuan proposal penelitian dan pengabdian bagi dosen masih dilakukan secara manual dan belum ada sistem online untuk mendukung dan mempermudah dalam proses pengajuan proposal dan penilaian proposal. Sedangkan untuk tingkat nasional sudah menggunakan sistem yang bernama Sistem Informasi Penelitian dan Pengabdian kepada Masyarakat atau disingkat simlitabmas yang bisa digunakan oleh semua dosen di Indonesia dalam mengajukan proposal penelitian dan pengabdian masyarakat untuk mendapatkan dana. Dalam rancang bangun sistem penelitian dan pengabdian ini, dibangun sistem seperti simlitabmas dari Risetdikti untuk memudahkan dosen dalam mengajukan proposal penelitian tingkat Universitas secara online serta dapat dilakukan penilaian proposal secara online oleh para aksesor tingkat universitas juga secara online. Dalam penelitian ini, dirancang sebuah Sistem Penelitian dan Pengabdian Dosen Berbasis Webserver secara online. Sistem ini dibuat dengan sistem terintegrasi berbasis web menggunakan PHP dan database MySQL. Sehingga tanpa mencetak proposal dan menghemat biaya cetak dan kertas, dosen dapat melakukan pengajuan proposal penelitian dan pengabdian masyarakat.

Kata Kunci : Database, Penelitian, Pengabdian Masyarakat, Web Server

\section{PENDAHULUAN}

Penelitian dan Pengadian Masyarakat merupakan kewajiban semua dosen Perguruan Tinggi di samping melakukan kegiatan pendidikan. Setiap dosen wajib melakukan penelitian dan pengabdian masyarakat untuk meningkatkan Jenjang Jabatan Akademik mereka dan melaksanakan Trri Dharma Perguruan Tinggi sesuai dengan peraturan
Undang Undang No. 12 Tahun 2012 tentang Perguruan Tinggi. Artinya semua dosen diwajibkan untuk melakukan kegiatan Pendidikan, Penelitian dan Pengabdian Masyarakat sebagai aturan yang harus diikuti tanpa terkecuali. Untuk itu, Kementrian RisetDikti membangun sistem yang disebut Sistem Informasi Penelitian dan Pengabdian Kepada Masyarakat atau disingkat simlitabmas yang dapat digunakan oleh semua dosen di 
Indonesia untuk mengajukan proposal penelitian dan pengabdian secara online. Di Universitas Bangka Belitung, pengelolaan penelitian dan pengabdian masyarakat dilakukan oleh Lembaga Penelitian dan Pengabdian Masyarakat (LPPM) yang mengelola semua proses penelitian dan pengabdian masyarakat di UBB baik tingkat universitas maupun tingkat nasional. Untuk tingkat nasional dosen UBB menggunakan simlitabmas dalam mengajukan proposal penelitian dan pengabdian masyarakat dan itu dapat dilakukan secara online. Tetapi untuk tingkat UBB, proses pengajuan dan pengelolaan penelitian dan pengabdian masyarakat dosen masih dilakukan secara manual mulai dari proposal, laporan kemajuan, laporan keuangan sampai laporan akhir. Hal ini akan membutuhkan biaya untuk cetak laporan serta kertas yang banyak. Tapi yang paling menyulitkan adalah untuk penyimpan semua laporan tersebut yang akan membutuhkan tempat penyimpanan yang banyak apabila dilakukan setiap tahun terus menerus. Untuk itu, diperlukan sebuah sistem yang mirip dengan simlitabmas agar dokumen dapat tersimpan secara digital dan dapat diakses kapan saja ketika diperlukan. Dengan sistem ini, dosen hanya perlu mengirimkan file proposal dan laporan kepada LPPM UBB melalui sistem penelitian dan pengabdian masyarakat serta asessor akan menilai proposal tersebut apakah proposal tersebut layak untuk diterima atau masih diperlukan perbaikan.

Secara umum sistem informasi ini dibangun dengan sistem terintegrasi berbasis web database. Web aplikasi ini menyimpan data seperti data dosen, data asessor, proposal, dan informasi penelitian dan pengabdian.

\section{METODE PENELITIAN}

Sistem Informasi Penelitian dan Pengabdian Masyarakat di UBB akan menggunakan web server untuk dapat diakses melalui Internet. Dengan sistem ini, semua proses penelitian dan pengabdian masyarakat di UBB oleh dosen dapat dilakukan secara online, mulai dari pengajuan proposal, laporan kemajuan, laporan keuangan dan laporan akhir serta penilaian oleh asessor juga dapat dilakukan secara online. Sistem ini dibuat untuk menggantikan sistem yang masih manual dan membutuhkan biaya cetak dan kertas dan tempat penyimpanan berkas yang luas. Sistem ini akan terintegrasi berbasis web database dengan menggunakan PHP dan MySQL. Web server ini menyimpan data seperti Data yang digunakan pada sistem ini adalah data dosen, asessor, proposal penelitian, proposal pengabdian dan data penilaian oleh asessor. Dan dapat diakses secara online.

Prosedur kerja pada penelitian ini terdiri atas beberapa tahapan. Tahapan yang dilakukan di dalam penelitian ini yaitu mengumpulkan data yang akan digunakan seperti data yang digunakan pada sistem ini adalah data dosen, asessor, proposal penelitian, proposal pengabdian dan data penilaian oleh asessor., Analisa sistem yang berjalan yang berjalan saat ini sehingga bisa merancang dan membangun sistem informasi yang baru, desain web server yang akan digunakan dosen dan asessor dan LPPM, membangun sistem penelitian dan pengabdian masyarakat yang dapat digunakan oleh dosen dan asessor, melakukan uji coba sistem untuk melihat apakah sistem sudah berjalan dengan baik atau telah sesuai dengan proses penelitian dan pengabdian yang ada di UBB, dan melakukan implementasi sistem penelitian dan pengabdian yang telah dibangun agar dapat digunakan oleh dosen, assessor serta LPPM UBB. Diagram alir penelitian dapat dilihat pada Gambar 1.

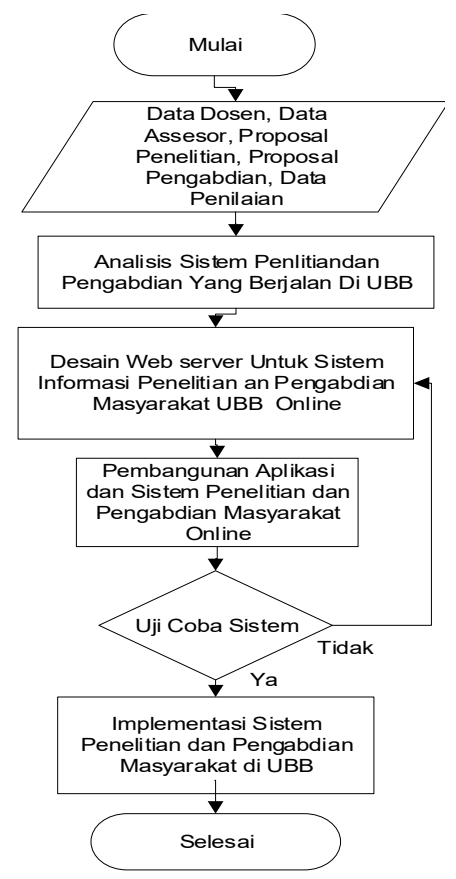

Gambar 1. Diagram alir penelitian 
Pada Gambar 2 dapat dilihat, perancangan sistem dibagi menjadi 3 (tiga) proses kerja diantaranya: proses pengaturan pedataan data asessor dan dosen oleh admin, login oleh dosen, asessor dan admin dan dosen sebagai peneliti mengupload proposal ke dalam sistem informasi dan Login asessor untuk melakukan penilaian proposal yang diajukan oleh dosen baik penelitian maupunpengabdian masyarakat dan meng upload hasil penilaian ke sistem untuk diterima oleh dosen dan LPPM UBB.

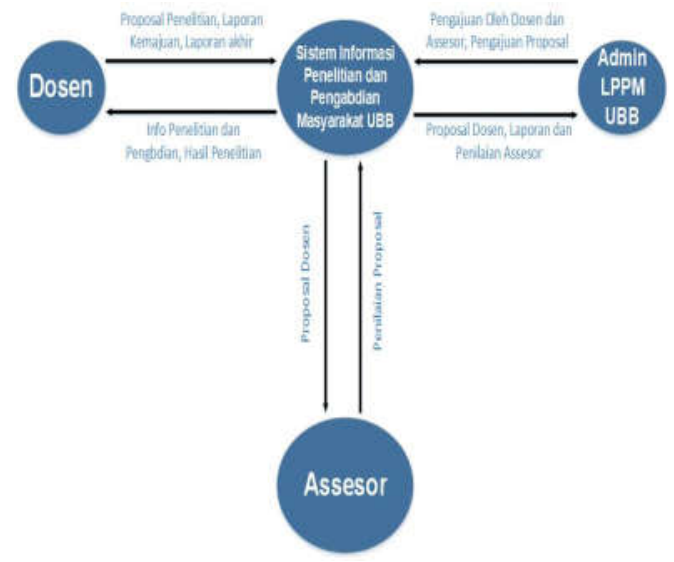

Gambar 2. Aliran data sistem penelitian dan pengabdian kepada masyarakat UBB

Pada Gambar 2 halamannjukkan bagaimana proses yang terjadi pada sistem penelitian dan pengabdian masyarakat di UBB ini agar lebih mudah dimengerti dan memudahkan dosen, asessor dan LPPM dalam proses mengelola penelitian dan pengabdian masyarakat di UBB.

Dapat dilihat proses aliran data antara dosen, asessor dan admin dalam menggunakan sistem ini sehingga dapat dilihat bahwa proses penelitian dan pengabdian berjalan secara online baik ketika proposal hingga laporan penelitian. Hal ini akan menghemat biaya cetak dan memudahkan proses bimbingan tugas akhir karena tidak tergantung waktu dan tempat karena tidak dilakukan dengan bertemu langsung antara mahasiswa dan pembimbing.

\section{HASIL DAN PEMBAHASAN}

Sistem Informasi Penelitian dan Pengabdian Masyarakat di UBB yang dibangun merupakan sistem informasi yang akan dapat diakses via Internet berbasis website dengan alamat situs adalah p2p.ubb.ac.id untuk memudahkan dalam melakukan proses penelitian dan pengabdian masyarakat secara online bagi dosen UBB dengan untuk membuat proses pengajuan proposal dan proses pelaporan penelitian dan pengabdian menjadi lebih mudah, hemat, cepat, efektif dan efesien. Sistem informasi yang diusulkan ini menyediakan beberapa fungsi dan fitur untuk memudahkan dosen, asessor dan LPPM sebagai berikut:

1. Penyimpanan draft proposal dan laporan penelitian dan pengabdian yang dibuat dosen UBB secara digital di dalam Sistem ini.

2. Menampilkan penilaian draft proposal yang di upload oleh dosen oleh asessor UBB dan dapat dilakukan secara online.

3. Adanya informasi kepada dosen yang mengajukan proposal apakah proposal diterima atau tidak serta kekurangan yang ada pada proposal tersebut.

4. Informasi tentang penelitian dan pengabdian pada masyarakat tingkat Universitas akan secara otomatis terisi berdasarkan tanggal dan waktu draft proposal yang diunggah dan dinilai oleh assessor.

5. Proposal dan revisi dapat di upload oleh dosen kapan saja dan dimana saja selama ada jaringan Internet untuk mengakses sistem serta masa untuk upload proposal belum ditutup.

6. Pengelolaan Sistem Informasi Penelitian dan Pengabdian Masyarakat di UBB ini dilakukan oleh admin dari LPPM UBB sehingga dapat melakukan kontrol terhadap proses penelitian dan pengabdian pada masyarakat seluruh dosen UBB.

\section{A. Tampilan Sistem Informasi}

Sistem Informasi Penelitian dan Pengabdian Masyarakat di UBB sudah dapat diakses online dengan alamat p2p.ubb.ac.id dimana dapat dilihat pada Gambar 3 tampilan utama dari sistem ini adalah halaman login, baik untuk admin, dosen dan asessor. Pada halaman ini, diharuskan memasukkan username dan password untuk dapat masuk ke dalam sistem ini. 


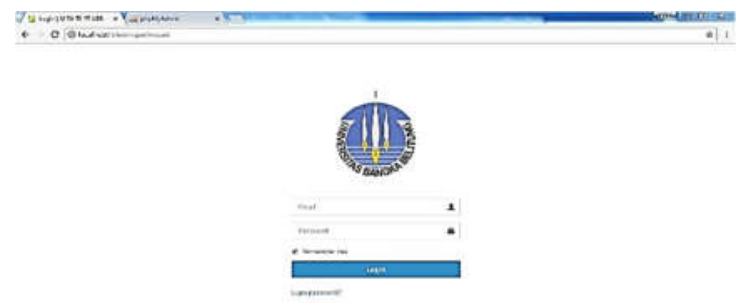

Gambar 3. Halaman login sistem

\section{B. Halaman Admin}

Pada Gambar 4, 5 dan 6, merupakan tampilan utama halaman untuk admin dalam melakukan pengelolaan sistem Informasi ini. Admin mempunyai kewenangan untuk membuat database dosen dan asessor serta melihat proses penelitian dan pengabdian yang berjalan. Admin juga mempunyai wewenang untuk membuat username dan password bagi dosen dan asessor. Pada Gambar 4, halaman yang ada pada admin adalah dashboard, kelola user yaitu admin, dosen dan asessor, rekapan nilai yang diperoleh dari penilaian oleh asessor.

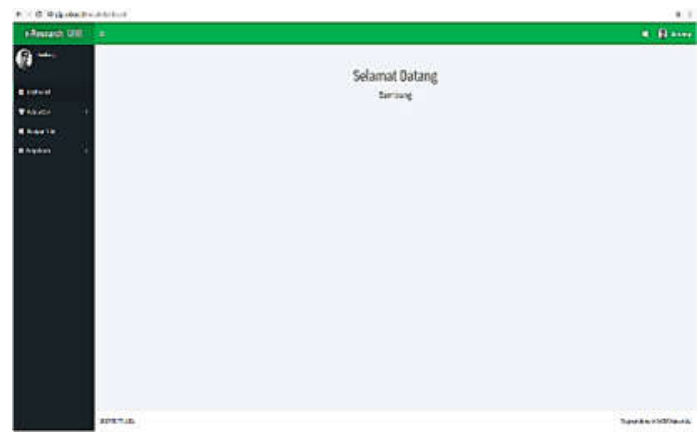

Gambar 4. Halaman utama admin

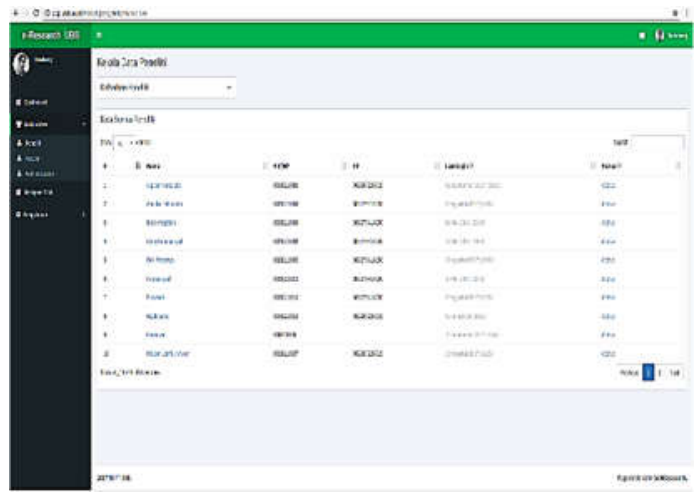

Gambar 5. Halaman pengelolaan data dosen dan asessor

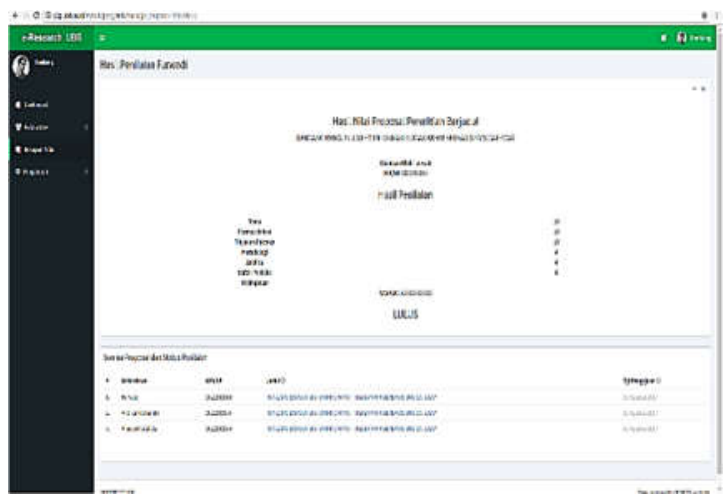

Gambar 6. Halaman rekapan nilai

\section{Halaman Dosen}

Pada Gambar 7, 8 dan 9, merupakan tampilan utama halaman untuk dosen sebagai peneliti dalam melakukan pengelolaan sistem ini. Dosen dapat melakukan proses upload proposal penelitian dan pengabdian masyarakat tingkat UBB dan mendapatkan nilai dari assesor untuk proposal tersebut. Dosen juga harus Login ke sistem sesuai dengan username dan password yang telah diberikan oleh admin. Pada Gambar 7, dapat dilihat halaman yang ada pada dosen adalah dashboard, proposal untuk melakukan proses upload dan pengaturan. Pada Gambar 8 adalah halaman untuk dosen melakukan proses pengajuan proposal ke LPPM yang sudah dilakukan secara online.

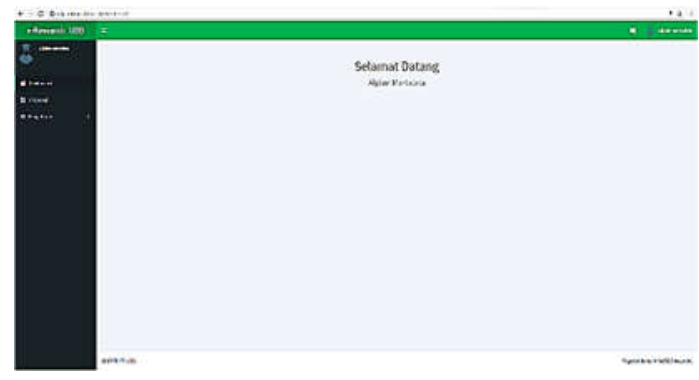

Gambar 7. Halaman utama dosen

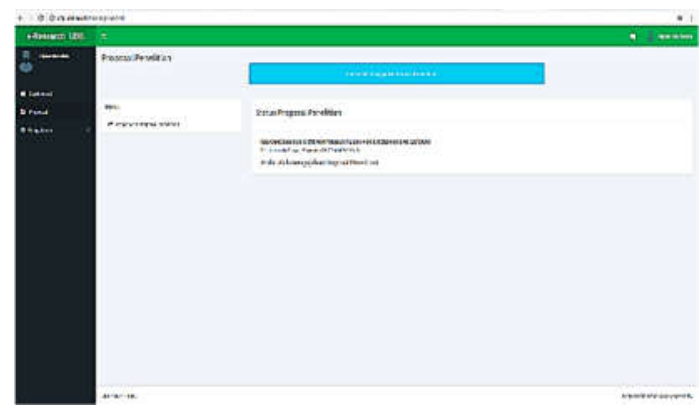

Gambar 8. Halaman proposal 


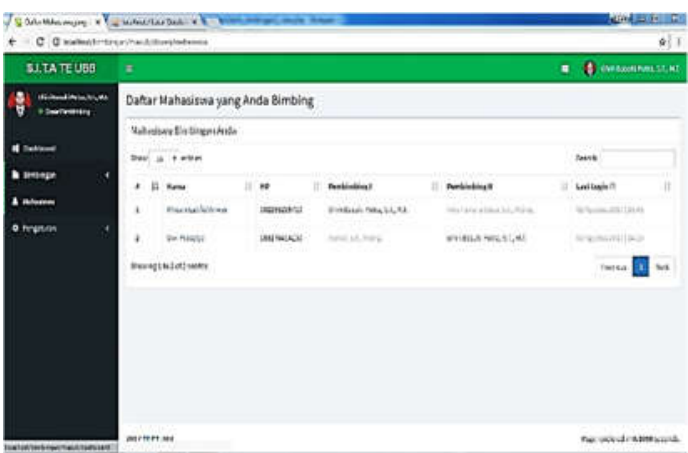

Gambar 9. Halaman pengaturan

\section{Halaman Asessor}

Pada Gambar 10, 11 dan 12, merupakan tampilan utama halaman untuk asessor dalam melakukan pengelolaan sistem informasi ini. Asessor dapat melakukan penilaian proposal penelitian dan melakukan proses download terhadap proposal dari dosen sebagai peneliti. Kemudian asessor dapat meng-upload hasil penelitian dari dosen peneliti ke sistem untuk dikelola admin LPPM UBB.

Asessor harus login ke sistem sesuai dengan username dan password yang telah diberikan oleh admin.

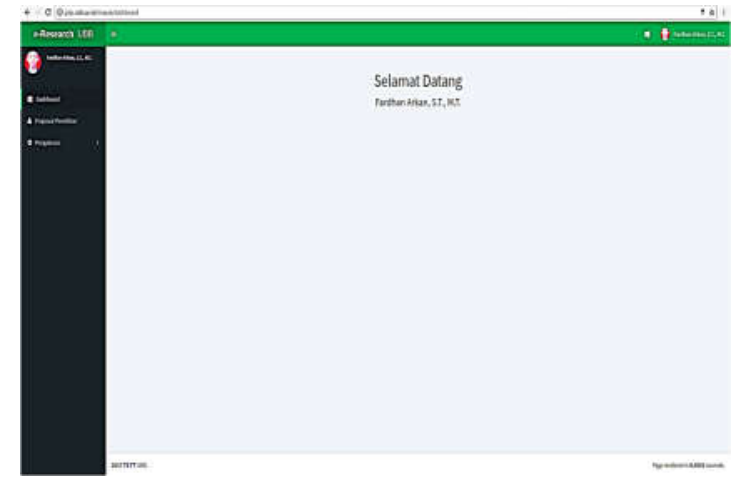

Gambar 10. Halaman Utama Asessor

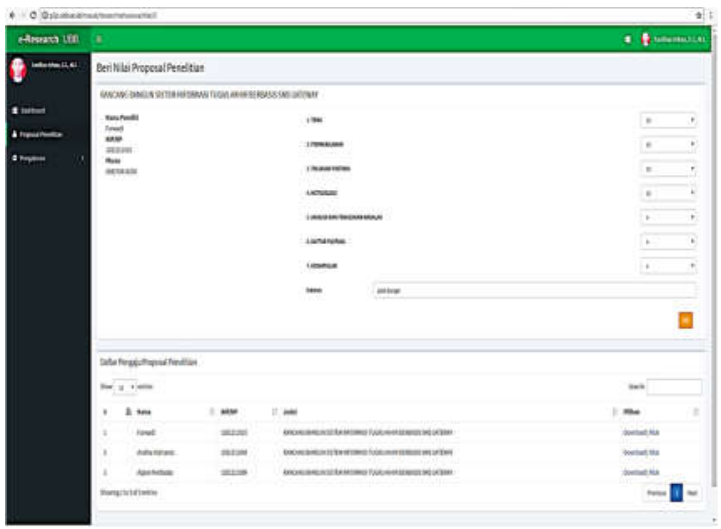

Gambar 11. Halaman penilaian asessor

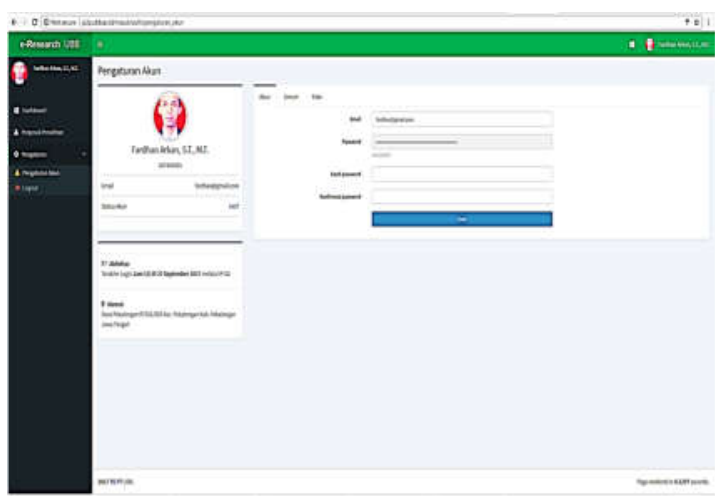

Gambar 12. Halaman login asessor

\section{KESIMPULAN}

Rancang bangun sistem informasi penelitian dan pengabdian masyarakat berbasis web server pada Universitas Bangka Belitung menggunakan PHP serta database MySQL yang merupakan sistem yang dibuat untuk memudahkan dosen, assesor dan LPPM UBB dalam melakukan pengelolaan proses penelitian dan pengabdian masyarakat secara online mulai dari pengajuan, penilaian sampai penyimpanan data. Serta sistem ini dapat memonitor proses kemajuan penelitian oleh dosen serta penilaian proposal oleh assesor. Dengan sistem ini proses pengajuan proposal oleh dosen dan penilaian oleh assesor dapat dilakukan kapan saja secara online sehingga menghemat waktu dan biaya.

\section{DAFTAR PUSTAKA}

[1]. Al Fatta. Hamid, A. F. (2007). Analisis dan Perancangan Sistem Informasi. Andi Publisher, Jogjakarta.

[2]. Hakim, L. (2013). Proyek Website Super Wow! PHP\&JQuery. Penerbit Lokomedia, Jogjakarta.

[3]. Setiaji, H., Kurniawan, R. (2011). Sistem Informasi dan Pengabdian Dosen Guna Otomasisasi Penentuan Angka Kredit Dosen dan Guna Mendukung Aktivitas TriDharma Perguruan Tinggi. Seminar Nasional Aplikasi Teknologi Informasi. ISSN:1907:5022. Jogjakarta.

[4]. Kadir, A. (2006). Pengenalan Sistem Informasi. Andi Publisher, Jogjakarta. 
[5]. Nugroho, L. E. (2009). Pemanfaatan Teknologi Informasi di Perguruan Tinggi. Prajnya Media, Jogjakarta.

[6]. Jumri, P., Jurista. (2013). Perancangan Sistem Monitoring Konsultasi Bimbingan Akademik Mahasiswa dengan Notifikasi Realtime Berbasis SMS Gateway. Jurnal Sistem dan Teknologi Informasi (JustIN), Vol 1, No 1.

[7]. Utami, E., \& Hartanto, A. D. (2012). Sistem Basis Data menggunakan Microsoft SQL Server 2005. Penerbit Andi, Jogjakarta. 